\title{
Role of Complement Regulatory Proteins (CD55, CD59, and CD35) on Red Blood Cells of $\beta$-Thalassaemia Patients
}

\author{
Hend Hanafy Mahmoud1, Nawal Mahrous Nasef ${ }^{1}$, Dalia Mahmoud Eldewi1, \\ Rasha Kamel Fathy Galal ${ }^{2}$ \\ ${ }^{1}$ Clinical Pathology Department, Faculty of Medicine for Girls, Al-Azhar University, Cairo, Egypt \\ ${ }^{2}$ Internal Medicine Department, Faculty of Medicine, Ain Shams University, Cairo, Egypt \\ Email: hendismail86@yahoo.com
}

How to cite this paper: Mahmoud, H.H., Nasef, N.M., Eldewi, D.M. and Galal, R.K.F. (2021) Role of Complement Regulatory Proteins (CD55, CD59, and CD35) on Red Blood Cells of $\beta$-Thalassaemia Patients. Open Journal of Blood Diseases, 11, 89-104.

https://doi.org/10.4236/ojbd.2021.114010

Received: August 31, 2021

Accepted: October 11, 2021

Published: October 14, 2021

Copyright $\odot 2021$ by author(s) and Scientific Research Publishing Inc. This work is licensed under the Creative Commons Attribution International License (CC BY 4.0).

http://creativecommons.org/licenses/by/4.0/

(c) (i) Open Access

\begin{abstract}
Background: $\beta$-thalassaemia ( $\beta$-Thal) is an inherited chronic haemolytic anaemia resulting from absent or low level of synthesis of $\beta$-globin chains of haemoglobin A in erythropoietic cells. The complement system is an important part of innate immune response that may be implicated in red blood cell (RBC) lysis. Mammalian cells are provided with surface bound complement regulatory proteins (MCRPs) that regulate the activation of complement cascade, thus protecting them from uncontrolled complement-mediated lysis. Objective is to evaluate the role of complement regulatory proteins (CD55, CD59, and CD35) on red blood cells, and to explain the pathogenesis of anaemia in $\beta$-thalassemia major. Methods: This case-control study enrolled $74 \beta$ thalassemia major patients who were compared with 40 age and sex matched controls. We performed expression of CD55, CD59, and CD35 on RBCs using flow cytometry. Results: CD55 levels of $\beta$-thalassemia major patients $(79.78 \% \pm 18.54 \%)$ were significantly decreased compared to healthy controls $(99.45 \% \pm 0.59 \%)(\mathrm{P}<0.001)$. CD59 levels of $\beta$-thalassemia major patients $(97.76 \% \pm 1.72 \%)$ were significantly lower than in the controls $(99.75 \%$ $\pm 0.36 \%)(\mathrm{P}<0.001)$, also CD35 levels were significantly lower in the $\beta$-thalassemia major patients $(4.30 \% \pm 4.66 \%)$ than in the control group $(19.40 \% \pm$ $10.90 \%)(\mathrm{P}<0.001)$. Conclusion: $\beta$-thalassemia major patients suffer from increased haemolysis and a consequent increase in their demand for blood transfusion. Complement-mediated haemolysis was shown in our study by decreased expression of CD55, CD59, and CD35 in $\beta$-thalassemia major patients. This allows complement deposition on RBCs and enhances or accelerates their lysis.
\end{abstract}


Keywords

CD55, CD59, CD35, $\beta$-Thalassemia Major

\section{Introduction}

$\beta$-thalassemia is one of the genetic diseases which can be broadly defined as a syndrome of inherited hemoglobin disorders characterized by a quantitative deficiency of functional $\beta$-globin chains. The defects involved are extremely heterogeneous and give rise to a large phenotypic spectrum, starting with patients that are almost asymptomatic to others in which regular blood transfusions are required to sustain life [1]. As a result of the inefficient synthesis of $\beta$-globin, the patients suffer from chronic anemia due to a process called ineffective erythropoiesis (IE) [2].

$\beta$-thalassaemia ( $\beta$-Thal) is considered a severe, progressive haemolytic anaemia, which needs regular blood transfusions for life expectancy [3]. Complement-mediated erythrocyte destruction can cause both intravascular and extravascular haemolysis. Complement regulatory proteins protect cells from such effects of the complement system [4].

The complement system is an evolutionarily primordial component of the innate immune response that functions through a series of over 30 coordinated cascading proteins and zymogens to protect the body from invading pathogens [5].

The proteins of the complement system can be found both in the plasma and as inactive precursors on the surface of cells within the body, and when activated by foreign pathogens lead to opsonization and eventual lysis of foreign cells. Though complement is an essential part of the immune response against microbes, the complement system also plays crucial roles in maintaining homeostasis through such mechanisms as the removal of apoptotic cells, the regulation of coagulation, angiogenesis, and lipid metabolism and, importantly, the surveillance of neoplastic cells [6].

Furthermore, as in all cases of homeostasis, just as the complement pathway can be activated, it too must be kept under the tight control of negative regulators so as to prevent excessive damage to self-tissues. Membrane-bound Complement Regulatory Proteins (mCRPs) is one such factor that exerts tight regulatory functions on the complement system thus protecting the body from the deleterious effects of overactive complement [7].

Decay accelerating factor (DAF, CD55) is a membrane-bound regulatory protein that downregulates the complement cascade at the critical step of $\mathrm{C} 3$ activation. It accelerates the decay of C3 and C5 convertases and thus prevents amplification of the complement cascade and formation of the membrane attack complex (MAC) [8]. CD59, a membrane-bound complement regulatory protein, inhibits the polymerization of $\mathrm{C} 9$ and it's binding to $\mathrm{C} 5 \mathrm{~b}-8$ through competitive 
inhibition of an epitope on C8, resulting in inhibition of MAC assembly and cell lysis [9]. Another membrane-bound protein CD35 (Complement receptor 1) plays an important role in the removal of immune complexes and pathogens coated with $\mathrm{C} 3 \mathrm{~b}$ and $\mathrm{C} 4 \mathrm{~b}$. It functions as a cofactor for the cleavage of $\mathrm{C} 3 \mathrm{~b}$ into iC3b. Additionally, CD35 binds to C4b and promotes the degradation of C4b into C4c and C4d [10]. Decreases in complement regulatory protein (CrP) levels may predispose RBCs to destruction by complement activation. So, complement regulatory proteins are absolutely required to protect $\mathrm{RBC}$ from spontaneous complement damage that contributes to the development of anaemia [11].

\section{Material and Methods}

\section{Subjects}

This study was conducted on 114 subjects at Al Zahraa University Hospital. Patients were selected from the outpatient clinic of Internal Medicine at Ain Shams University Hospitals in the period from $1 / 5 / 2018$ to $29 / 1 / 2019$. Subjects were divided as follows:

Patients group: $74 \beta$-thalassemia major patients ( 2 - 53 years old) 29 were males and 45 were females.

Control group: They were 40 age and sex matched healthy subjects as a control group ( 3 monthes- 66 years old) 17 were males and 23 were females.

Exclusion criteria include:

Recently splenectomized patients (within the past 6 months).

Presence of comorbidities (inflammation, infection \& chronic diseases) at time of sampling.

Presence of other hereditary diseases.

Inheritance of other $\mathrm{Hb}$ disorders.

Pregnant or lactating females.

Non Egyptians and those of foreign ancestory.

Ethical consideration:

The study takes into consideration the basic principle of biomedical ethics for participant patients. Free and voluntary written informed concent was obtained from patients or their mothers. Gardians were informed about their absolute rights to be involved or, to withdraw at any time of the study. Personal privacy and confidentiality of the corrected data was secured.

\section{Methods}

The following was performed for all subjects:

Clinical assessment: (full family history and thorough clinical examination) and calculation of body mass index (BMI) according to the following equation; $\mathrm{BMI}=$ weight in $(\mathrm{Kg}) /$ height in $\left(\mathrm{m}^{2}\right)$.

Laboratory tests:

Complete blood picture using the Beckman Coulter HmX hematology analyser, Manual Reticulocytic count and ESR.

Liver function tests (ALT, AST, total and direct bilirubin, $\gamma$ GT, alkaline phosphatase) and Kidney function tests (BUN, creatinine) using Unicel DXC 600 
"Synchron clinical system".

$\mathrm{Hb}$ electrophoresis using electrophoresis tank HL 77704, scanning densitometer Helena process 24 (Helena laboratories, Beaumont and Texas).

Iron profile (serum iron, TIBC, serum ferritin) using Unicel DXC 600 "Synchron clinical system" \& Access 2 "immunoassay system".

Expression of CD55, CD59, and CD35 on RBCs (or erythrocytes) was performed using four colors flow cytometry FACS Calibur (BD Biosciences, San Jose, USA) using system software Cell Quest Pro.

\section{Sample Collection}

For each case, $7 \mathrm{~mL}$ of whole venous blood were withdrawn under complete aseptic conditions. $2 \mathrm{~mL}$ of which were collected on ethylene diamine tetra-acetic acid (EDTA) as an anticoagulant, to be used for performing CBC, preparation of Leishman stained peripheral blood (PB) smears and reticulocytic count and other $2 \mathrm{ml}$ on EDTA for flow cytometric immunophenotyping (IPT). The sample was then stored at $4^{\circ} \mathrm{C}$ (for not more than one week) to perform $\mathrm{Hb}$ electrophoresis.

The other $3 \mathrm{~mL}$ of venous blood were collected into a sterile dry vacutainer and was left to clot for 30 minutes in the vacutainer. Serum was then separated by centrifugation at $500 \mathrm{~g}$ for 15 minutes for measuring liver and kidney function tests, iron profile assays (serum iron, TIBC and serum ferritin).

Flow Cytometric Analysis of CD55, CD59, and CD35 on the Cell Membrane of Red Blood Cells (RBC).

Monoclonal antibodies used:

Fluorescein isothioocyanate (FITC)-conjugated anti-human CD35 and CD59 (Lot No. 30, 40 respectively).

Phycoerythrin (PE)-conjugated anti-human CD55 (Lot No.40).

All monoclonal antibodies were obtained from Immunotech, Bechman, Marseille, France.

The optimal concenteration of each antibody was determined by the experiment.

Staining the cells: for each patient sample, two tubes were labelled with the sample identification number.

The blood sample was diluted with phosphate-buffered saline (PBS) to achieve $10,000 \mathrm{RBC} / \mu \mathrm{l}$ concentration. Then $100 \mu \mathrm{l}$ of diluted blood was transferred to each one of the labeled tubes.

$10 \mu \mathrm{l}$ of each monoclonal Ab against CD55 (PE Mouse Anti-Human), CD59 (FITC Mouse Anti-Human), and CD35 (FITC Mouse Anti-Human) was placed into one of the labeled tube, vortexed thoroughly at low speeds for 3 seconds and incubated for 30 minutes in the dark at room temperature $\left(20^{\circ} \mathrm{C}\right.$ to $\left.25^{\circ} \mathrm{C}\right)$.

$10 \mu \mathrm{l}$ of the isotype matched control was added to the control tube.

$2 \mathrm{ml}$ PBS were added two times, vortexed thoroughly at low speed for 3 seconds. Then centrifuged at $200 \times \mathrm{g}$ for 5 minutes at room temperature $\left(20^{\circ} \mathrm{C}\right.$ to $\left.25^{\circ} \mathrm{C}\right)$. 
The supernatant was aspirated leaving approximately $50 \mu \mathrm{l}$ of residual fluid in each tube to avoid disturbing the pellet.

$200 \mu \mathrm{l}$ of PBS was added to each tube to resuspend the cell pellet and vortexed for 5 seconds. Analysis was performed within 2 hours following immunostaining in a four colors flow cytometer (FACS Calibur, Becton-Dickinson).

\section{Statistical Analysis}

Data were coded and entered using the statistical package for the Social Sciences (SPSS) version 26 (IBM Corp., Armonk, NY, USA).

\section{Descriptive Statistics}

Data was summarized using mean, standard deviation, median, minimum and maximum in quantitative data and using frequency (count) and relative frequency (percentage) for categorical data.

$$
\text { Mean }=\sum x / n
$$

where $\Sigma=$ sum and $n=$ number

Standard deviation:

Formula

$$
s=\sqrt{\frac{\sum(X-\bar{x})^{2}}{n-1}}
$$

\section{Explanation}

$s=$ sample standard deviation

$\Sigma=$ sum of...

$X=$ each value

$\bar{X}=$ sample mean

$n=$ number of values in the sample

\section{Analytical Statistics}

Mann Whitney Test (U test): was used to compare two study groups with quantitative but non-parametric variables.

Chi-Square test (c2): was used to compare categorical data. Exact test was used instead when the expected frequency is less than 5.

Spearman correlation coefficients: were used to assess the correlation between two quantitative parameters in the same group.

The probability of being by chance (P-value): It was calculated for all parameters and less than 0.05 was considered as statistically significant.

The $P$ value was considered significant as the following:

$P \geq 0.05$ : Non significant.

$\mathrm{P}<0.05$ : Significant.

$\mathrm{P} \leq 0.001$ : Highly significant.

\section{Results}

The patients had been previously diagnosed by clinical and laboratory examinations including $\mathrm{Hb}$ electrophoresis and complete blood count. The haematological parameters of the patients and controls are summarised in Table 1. The 
Table 1. Comparison between patients group versus control group as regards CBC parameters and Retics.

\begin{tabular}{|c|c|c|c|c|c|c|c|}
\hline & \multicolumn{3}{|c|}{$\begin{array}{c}\text { Cases } \\
(n=74)\end{array}$} & \multicolumn{3}{|c|}{$\begin{array}{c}\text { Controls } \\
(n=40)\end{array}$} & \multirow[t]{2}{*}{$P$ value } \\
\hline & Mean \pm SD & Median & Range & Mean \pm SD & Median & Range & \\
\hline WBCs $\left(/ \mathrm{mm}^{3}\right)$ & $17.40 \pm 19.15$ & 10.20 & $1.80-36.80$ & $8.12 \pm 2.68$ & 7.25 & $4.90-18.10$ & $0.011^{*}$ \\
\hline $\mathrm{RBCs}\left(/ \mathrm{mm}^{3}\right)$ & $3.32 \pm 0.66$ & 3.26 & $1.51-5.63$ & $4.54 \pm 0.52$ & 4.51 & $3.30-5.50$ & $<0.001^{*}$ \\
\hline $\mathrm{Hb}(\mathrm{g} / \mathrm{dL})$ & $8.06 \pm 1.37$ & 8.10 & $3.79-11.80$ & $12.88 \pm 0.99$ & 12.75 & $11.50-16.00$ & $<0.001^{*}$ \\
\hline HCT (\%) & $24.32 \pm 4.47$ & 24.90 & $8.51-35.10$ & $36.49 \pm 3.57$ & 36.05 & $30.00-46.90$ & $<0.001^{*}$ \\
\hline $\operatorname{MCV}(\mathrm{Fl})$ & $73.97 \pm 8.45$ & 75.35 & $56.30-89.20$ & $80.19 \pm 5.89$ & 80.40 & $58.40-89.60$ & $<0.001^{*}$ \\
\hline $\mathrm{MCH}(\mathrm{pg})$ & $24.66 \pm 3.25$ & 25.35 & $16.30-30.20$ & $27.73 \pm 2.28$ & 28.00 & $21.20-32.80$ & $<0.001^{*}$ \\
\hline $\mathrm{MCHC}(\mathrm{g} / \mathrm{dL})$ & $33.41 \pm 3.14$ & 33.15 & $24.90-44.50$ & $34.24 \pm 1.70$ & 34.50 & $26.90-37.40$ & $0.005^{*}$ \\
\hline RDW (\%) & $31.84 \pm 83.72$ & 20.15 & $12.10-38.40$ & $13.79 \pm 1.57$ & 13.65 & $11.80-20.50$ & $<0.001^{*}$ \\
\hline Platelets $\left(\times 10^{3} / \mathrm{uL}\right)$ & $571.66 \pm 358.39$ & 515.00 & $62.40-1744.00$ & $287.02 \pm 79.72$ & 269.50 & $150.00-471.00$ & $<0.001^{*}$ \\
\hline Retics (\%) & $7.76 \pm 1.55$ & 7.80 & $5.00-10.00$ & $0.84 \pm 0.38$ & 0.80 & $0.20-1.80$ & $<0.001^{*}$ \\
\hline
\end{tabular}

${ }^{\star}$ Highly significant as $\mathrm{P}$ value $<0.001 .{ }^{\star}$ Significant as $\mathrm{P}$ value $<0.05 .{ }^{\star}$ Non significant as $\mathrm{P}$ value $>0.05$.

levels of CD55, CD59, and CD35 expressions on peripheral blood erythrocytes by flow cytometric analysis were compared between two groups, $\beta$-thalassemia major patients, and control groups, as shown in Table 2 . The overall (mean \pm $\mathrm{SD})$ percentage of CD55-positive RBCs of $\beta$-thalassemia major patients was significantly lower $(79.78 \pm 18.54 \%)$ than healthy controls $(99.45 \pm 0.59 \%)(\mathrm{p}<$ 0.001). The overall mean percentages of CD59-positive RBCs of $\beta$-thalassemia major patients $(97.76 \pm 1.72 \%)$ was significantly lower than controls $(99.75 \pm$ $0.36 \%)(\mathrm{p}<0.001)$. The overall mean percentage of CD35-positive RBCs of $\beta$-thalassemia major patients was significantly lower $(4.30 \pm 4.66 \%)$ than healthy controls $(19.40 \pm 10.90 \%)(\mathrm{p}<0.001)$. Figure 1 represents scattering of RBCs stained with anti-CD55 PE, anti-CD59 FITC, and anti-CD35 FITC in healthy controls. Figure 2 represents scattering of RBCs stained with anti-CD55 PE, anti-CD59 FITC, and anti-CD35 FITC in $\beta$-thalassemia major patients.

In our study, there is highly significant positive correlation of CD59\% on RBCs with MCV ( $r s=0.393, \mathrm{P}=0.001$ ), significant negative correlation of CD55\% on RBCs with MCV ( $r s=-0.286, \mathrm{P}<0.05$ ), and no significant correlation of CD35\% on RBCs with MCV ( $r s=0.047, \mathrm{P}>0.05$ ). Also, there is significant negative correlation of CD55\% on RBCs with Reticulocytic count ( $r s=$ $-0.267, \mathrm{P}<0.05)$.

In our study, there is significant positive correlation of CD55\% on RBCs with $\mathrm{RBC}$ count $(r s=0.321, \mathrm{P}<0.05)$. Also, there is highly significant positive correlation of $\mathrm{CD} 35 \%$ on RBCs with WBC count $(r s=0.416, \mathrm{P}<0.001)$. In addition, there is significant higher values of platelets among patients compared to controls $(\mathrm{P}>0.001)$. 
Table 2. Comparison between patients group versus control group as regards CD55\%, CD59\%, and CD35\%

\begin{tabular}{|c|c|c|c|c|c|c|c|}
\hline & \multicolumn{3}{|c|}{$\begin{array}{c}\text { Cases } \\
(n=74)\end{array}$} & \multicolumn{3}{|c|}{$\begin{array}{l}\text { Controls } \\
(n=40)\end{array}$} & \multirow{2}{*}{$P$ value } \\
\hline & Mean \pm SD & Median & Range & Mean \pm SD & Median & Range & \\
\hline$\%$ CD55 RBCs & $79.78 \pm 18.54$ & 84.35 & $0.05-98.20$ & $99.45 \pm 0.59$ & 99.60 & $97.30-100.00$ & $<0.001^{*}$ \\
\hline \%CD59 RBCs & $97.76 \pm 1.72$ & 98.07 & $90.33-99.79$ & $99.75 \pm 0.36$ & 99.90 & $98.40-100.00$ & $<0.001^{*}$ \\
\hline$\%$ CD35 RBCs & $4.30 \pm 4.66$ & 2.92 & $0.10-26.38$ & $19.40 \pm 10.90$ & 17.90 & $5.40-49.60$ & $<0.001^{*}$ \\
\hline
\end{tabular}

${ }^{\star}$ Highly significant as $\mathrm{P}$ value $<0.001 .{ }^{*}$ Significant as $\mathrm{P}$ value $<0.05 .{ }^{\star}$ Non significant as $\mathrm{P}$ value $>0.05$.
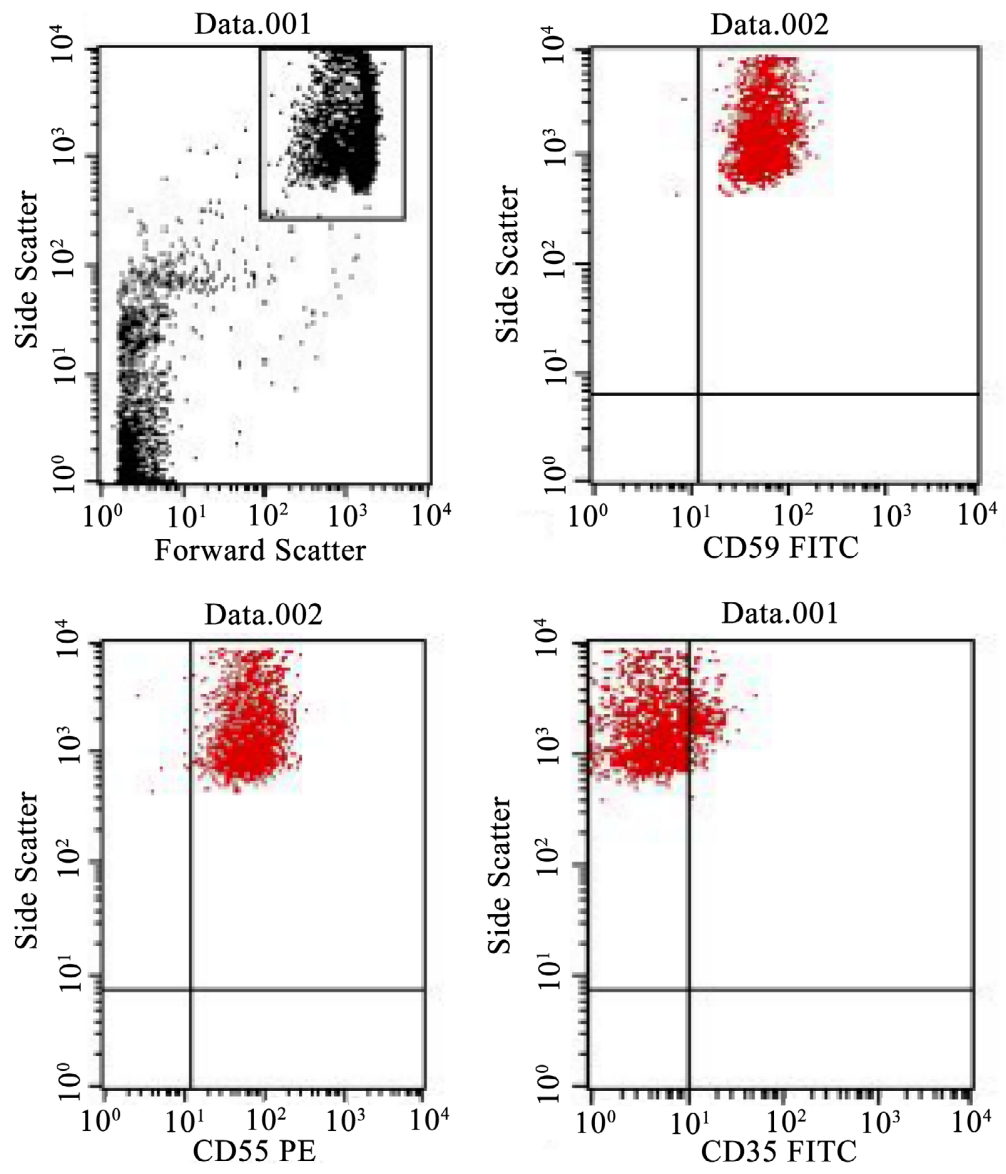

Figure 1. Dot plot results of erythrocytes analyzed by flow cytometry. Red blood cells were gated on the basis of their forward and side scatter. Dot plot showed CD35 PE, CD59 FITC and CD55 PE expression on the gated RBCs of healthy controls.

Also, in our study, there is highly significant positive correlation of CD55\% ( $r s$ $=0.573, \mathrm{P}<0.001)$ and $\mathrm{CD} 35 \%$ ( $r s=0.575, \mathrm{P}<0.001)$ on RBCs with age, but there is there is no significant correlation of CD59\% on RBCs with age ( $r s=$ $0.048, \mathrm{P}>0.05)$. In addition, there is no significant correlation $(\mathrm{P}>0.05)$ of CD55\%, CD59\%, and CD35\% on RBCs with urea, creatinine, LDH, bilirubin, ferritin, and CRP. There is no significant difference $(\mathrm{P}>0.05)$ between patients and control groups as regards age and sex. 

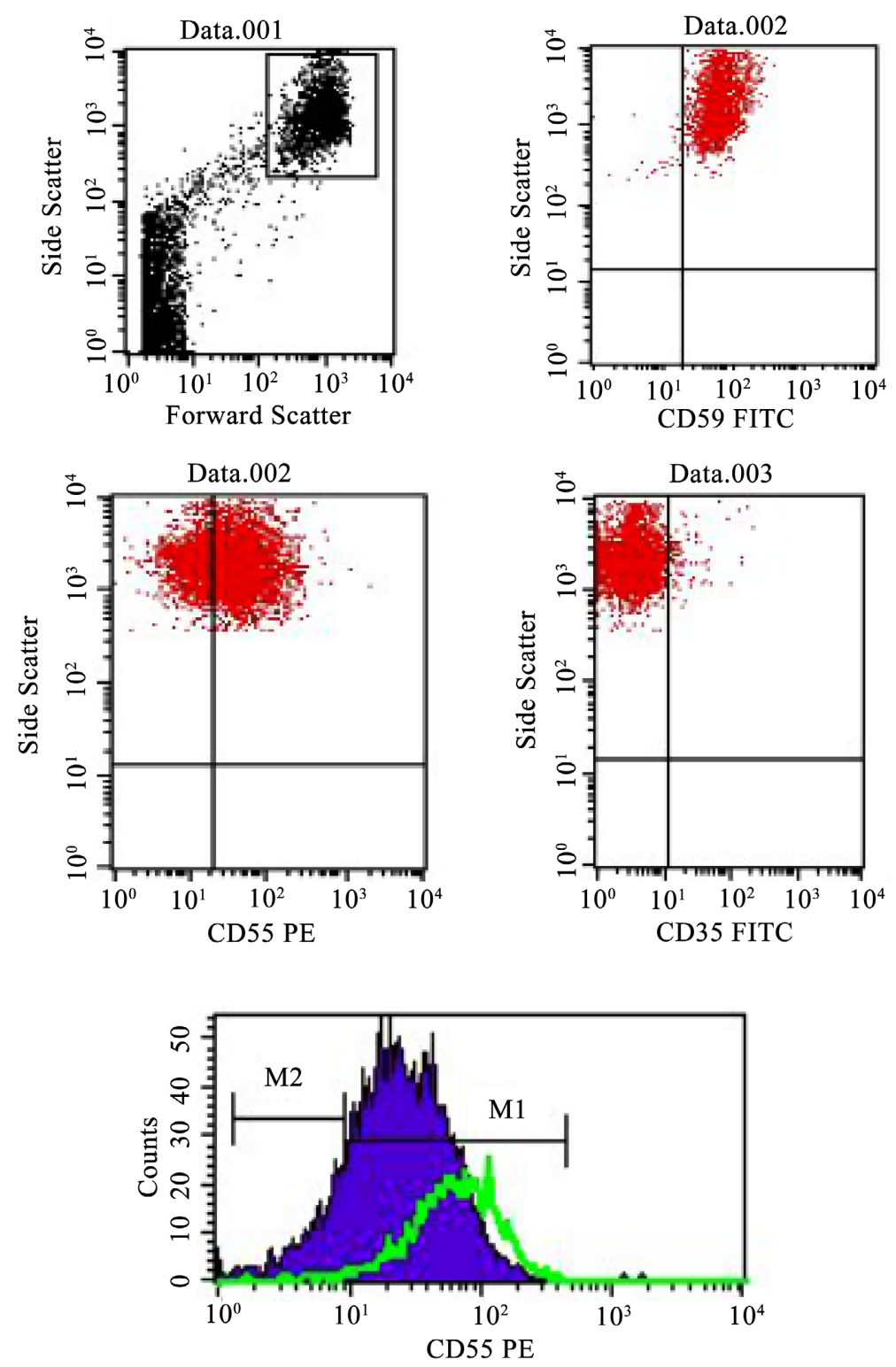

Figure 2. Dot plot results of erythrocytes analyzed by flow cytometry. Red blood cells were gated on the basis of their forward and side scatter. Dot plot showed CD35 PE, CD59 FITC and CD55 PE expression on the gated RBCs of $\beta$-TM patients.

\section{Discussion}

The thalassemias are a group of inherited disorders that are caused by altered or absent hemoglobin chain synthesis leading to ineffective erythropoiesis and subsequent anemia. It is the most common genetic disorder worldwide and occurs in approximately 4.4 of every 10,000 live births. Three main clinical forms have been described: thalassemia major, thalassemia intermedia and thalassemia minor [12].

Beta thalassemia major is a congenital hemolytic anemia caused by defects in beta globin chain synthesis. The $\alpha$-globin chain that is produced in excess is responsible for the ineffective erythropoiesis and shortened red blood cell survival. 
In the absence of their partners, the unstable free $\alpha$-globin chains are not able to form viable tetramers and instead precipitate in the red cell precursors in the bone marrow, giving rise to intracellular inclusions which interfere with red cell maturation resulting in variable degrees of intramedullary destruction of red cell precursors. Blood transfusion is the mainstay of the care of individuals with thalassemia major [2].

Chronic blood transfusions for patients with severe $\beta$-TM leads to iron overload which is a major source of morbidity and mortality in both transfusiondependent and non-dependent thalassaemia patients necessitating iron chelation therapy. Three approved iron chelation agents are available currently: deferoxamine, deferiprone and deferasirox, with the approval and availability of these agents largely country specific [13]. Haemolysis is a common feature in patients with $\beta$-TM. Ineffective erythropoiesis and haemolysis leads to the conspicuous anaemia seen in the $\beta$-TM, which can be corrected with repeated blood transfusions [14].

In $\beta$-Thal, $\mathrm{RBC}$ destruction is related mainly to the changes occurring in the cell membrane, which can activate the complement deposition on RBCs. In addition, elicited auto-antibodies against the red cell membrane will sensitise RBCs and make them ready to be lysed via the reticuloendothelial system. Complement activation on the RBCs causes cell lysis, but these cells have regulator proteins that prevent lysis [15].

Formation of autoantibodies against RBCs, in association with RBCs alloimmunization, has been documented in previous studies. Autoantibodies are directed against the individual's own RBCs which can result in clinical hemolysis and difficulty in the crossmatching procedure. Patients with autoantibodies may have a higher transfusion rate and often require immunosuppressive drugs, splenectomy or alternative treatments [13].

$\beta$-TM patients require frequent blood transfusions to live. Blood transfusion causes the transmission of autoantibodies of the donor to the recipient. Complement cascade is activated via autoantibodies in transfusion-dependent $\beta$-TM patients. Particularly functions of CD35 include control of complement activation and the clearance of immune complexes [16].

Normal cell membranes express CrPs that regulate activation of the complement system and provide essential protection against self-damage. Many studies show that CrPs may play an important role in protecting $\mathrm{RBC}$ from destruction through the activation of complement. A number of haemolytic disorders are caused by mutations and/or autoantibodies that inactivate CrPs and mutations that directly activate the complement cascade [17].

Haemolysis and related complications play a very important role in $\beta$-TM patients, but studies about cascade system aiming to understand the aetiopathogenesis of the haemolysis are fewer in number. Most of the present studies are related to CD55 and CD59 levels, but there are not enough data about CD35 levels in $\beta$-thalassemia patients, so we think that our study draws attention to the role of the complement system in the aetiopathogenesis of $\beta$-thalassaemia major due 
to the low level of expression of CD35 detected in our study.

In this study, we measured CD35 levels as well as CD55 and CD59 levels in $\beta$-thalassaemia major patients. We found a high significant difference between studied groups as regards CD55\%, CD59\%, and CD35\% on RBCs with significantly decreased expression of CD55\%, CD59\%, and CD35\% on RBCs were found among patients compared to controls.

In line with our findings, Obaid et al., Kurtoğllu et al., and Zahran et al. found that expression of CD55 levels of $\beta$-thalassaemia patients were significantly decreased compared to healthy controls. On the other hand, they found there was no significant difference in the percentage of CD59 marker expression between $\beta$-thalassaemia patients and healthy controls [11] [18] [19].

Obaid et al. suggested that the mechanism responsible for low CD55 expression could be genetic. It may be related to defective $\mathrm{Hb}$ genes in thalassemia, but it does not relate to cell membrane changes [18]. CD55 prevents C3 and C5 activation through all complement pathways by inhibiting formation and accelerating decay of $\mathrm{C} 3 / \mathrm{C} 5$ convertases of both the classical and alternative pathways [20].

Obaid et al. also found that compensation of CD55 underexpression to minimize the hemolysis occurring in $\beta$-thal patients occurred when an increase in the mean fluorescence intensity (MFI) of both the receptor CD55, on the positive cells, and another complement inhibitor receptor CD59 [21].

The two red cell surface complement regulators, CD55 and CD59, are GPI (glycosylphosphatidylinositol)-linked proteins. Somatic mutation in phosphatidylinositol glycan class A (PIG-A) gene causes a deficiency of glycosylphosphatidylinositol (GPI), a glycolipid that anchors these proteins onto the cell membrane. Lack of GPI causes loss of CD55 and CD59, leading to excessive destruction of red cells in PNH [22].

This could explain why in our study the CD55 and CD59 expression on the RBCs of $\beta$-thalassemia major patients was diminished to below that of the healthy controls, with a statistical significance. In other studies CD59 expression was not affected. So other studies indicate that the affected cells have normal GPI-anchored type 1 surface proteins, and consequently they are not PNH clones, but our study does not support that, so this point needs further studies to clarify it.

Repeated transfusions for the treatment of thalassaemia major cause an insult to the patient's immune system and provoke post-transfusion purpura and haemolytic reactions that can be severe and life threatening. Salama et al. found that thalassaemia patients exposed to multiple antigens through repeated blood transfusions showed lower CD59 expression than did those who had received fewer transfused units, which is a good method of detecting potential autoantibodies [23]. Repeated blood transfusions may also provide an explanation why there is low CD59 percentage expression on RBCs of $\beta$-thalassemia major patients in our study. 
In line with our findings, Kurtoğllu et al. found that expression of CD35 levels were significantly lower in the $\beta$-TM patients and $\beta$-TI patients compared to the control group [11].

The reason for the low level of CD35 may be a genetic defect related to the synthesis of the proteins. There are more than 300 gene mutations defined in $\beta$-Thal patients in the literature. Some of these mutations may alter the synthesis of CD35 in the erythrocytes. The mean number of CD35 molecules expressed on the RBC surface varies between individuals, typically between 50 and 1500 CD35 molecules/RBC. Factors determining the variation in RBC CR1 expression are not fully understood, but are proposed to be both genetic and acquired [24].

The CD35/CR1 for C3b of erythrocytes has already been shown to bind complement-activating bacteria, viruses, and immune complexes, and deliver immune complexes to the fixed macrophages of liver and spleen. CR1 is a receptor for both $\mathrm{C} 3 \mathrm{~b}$ and $\mathrm{C} 4 \mathrm{~b}$ and plays an important role in the removal of immune complexes coated with C3b and C4b [17].

The MCV value was found to be significantly lower in both $\beta$-TM and $\beta$-TI patients compared to the healthy population, consistent with the literature. Opi et al. found that CD35 levels are low on the surface of erythrocytes in patients with $\alpha$-thalassaemia. Also, it was stated that the low level of CD35 is related to the MCV value of these patients [25]. Changes caused by excess $\alpha$-globin tetramers on erythrocyte membrane may lead to low levels of CD35 and CD55 on the erythrocytes. Also, increased vesiculation has been documented in $\alpha+$ thalassaemia RBCs, which might therefore provide a mechanism for CR1 loss. It remains unclear whether microcytic RBC synthesis is due to lower amounts of CR1 in $\beta$-Thal than normal cells, or whether some CR1 is lost, for example, through exocytosis of membrane vesicles during normal $\mathrm{RBC}$ ageing, as well as by proteolysis [11].

On the other hand, in our study, there is significant negative correlation of CD55\% on RBCs with MCV and no significant correlation of CD35\% on RBCs with MCV, but there is highly significant positive correlation of CD59\% on RBCs with MCV. This means that our study does not support that low levels of $\mathrm{CD} 55 \%$ and $\mathrm{CD} 35 \%$ are related to low MCV value in $\beta$-thalassemia major patients. We think that studies concerning the synthesis and destruction of CD55, CD59, and CD35 proteins will provide a positive effect on the prognosis of $\beta$-thalassemia major patients.

Salama et al. found that CD59 expression showed a negative correlation with reticulocytosis in $\beta$-thalassaemia major patients. Also, a negative correlation between CD59 expression and normoblast count denotes ongoing minimal lysis of red cells, which was not apparent clinically. This work suggests that measurement of CD59 expression can be used as a predictor of subclinical complement-activated haemolysis that is insufficient to produce a positive direct antiglobulin test [23].

On the other hand, in our study, there is no significant correlation of CD59\% and CD35\% on RBCs with Reticulocytic count, but there is significant negative 
correlation of CD55\% on RBCs with Reticulocytic count which could also denote ongoing minimal cell lysis.

Zahran et al. found mild significant positive correlation between CD55 expression and hemoglobin level in all $\beta$-thalassaemia major patients, so this observations indicate that a decrease in RBCs destruction accompanied by increasing CD55 expression [19]. On the other hand, in our study, there is no significant correlation of CD55\%, CD59\% and CD35\% on RBCs with hemoglobin level.

Obaid et al. found negative correlation between decreased CD55 expression on RBCs and platelet count. The shedding of CD55 molecule from RBCs may be gained by platelets and increase their survival. Thus, platelet count showed elevation [18]. In line with this finding, there is significant higher values of platelets among patients compared to controls in our study.

In our study, there is significant positive correlation of CD $55 \%$ on RBCs with $\mathrm{RBC}$ count. This can be explained by the shedding of CD55 molecule from RBCs that may decrease their survival and their count.

Also, in our study, there is highly significant positive correlation of CD $35 \%$ on RBCs with WBC count. This may denote that low level of CD35 may be due to gene mutation causing low level of CD35.

In our study there is highly significant positive correlation of $\mathrm{CD} 55 \%$ and $\mathrm{CD} 35 \%$ on RBCs with age, but there is there is no significant correlation of CD59\% on RBCs with age. This may be due to a genetic defect related to the synthesis of the proteins.

In our study, there is no significant correlation of CD55\%, CD59\%, and $\mathrm{CD} 35 \%$ on RBCs with urea, creatinine, $\mathrm{LDH}$, bilirubin, ferritin, and CRP. There is no significant difference between patients and control groups as regards age and sex.

CD55, CD59, and CD35 proteins on the cell surfaces block complement activation. Loss of these proteins makes the blood cell susceptible to haemolysis. There are studies of CD55, CD59, and CD35 levels in diseases having a haemolytic course, such as malaria, paroxysmal nocturnal haemoglobinuria, and autoimmune haemocytopaenia [26].

Arora et al. found that DAF and CD59 receptor expression on erythrocytes from RA patients was significantly lower than on those from normal individuals. This indicates abnormality in DAF and CD59 expression in RA patients, and the observed decreases could be the likely consequences of the disease process. Correlation between decreased CD59 and DAF in the RA patients was significant. Deficiency of DAF on the erythrocyte membrane, as in paroxysmal nocturnal haemoglobinuria, leads to unrestricted complement activation and haemolysis. It has been previously reported that the expression of the complement receptor, CR1, on erythrocytes is reduced in patients with RA and that the reduced expression of CR1 is related to disease activity [27].

Barros et al. showed that the expression of CD47 on RBCs of patients with warm autoimmune haemolytic anaemia is not different from that seen in healthy 
individuals. In addition, they detected that patients with active warm-type auto immune haemolytic anaemia present lower expression of CD59 and normal expression of $\mathrm{CD} 35$ and $\mathrm{CD} 55$ on their RBCs. Complement-regulatory proteins may play an important role in protecting $\mathrm{RBC}$ destruction through the activation of complement [28].

Alegretti et al. showed decreased CD55 and CD59 expression on RBCs of SLE patients with nephritis. The results suggest there is an altered pattern of complement regulatory proteins expression on the peripheral blood cells of SLE patients, and the expression is correlated with disease activity and/or with activation of the complement system [20].

Al-Faris et al. found that the number of CKD patients with CD59 deficiency was significantly higher compared to the healthy controls, and there were increased proportions of CD55- and CD59-deficient RBCs among CKD patients with various disease stages compared to healthy controls. The strength of CD59 expression on RBCs in the CKD patients, as shown by MFI, was also significantly lower than that in healthy controls. In this study, it could be speculated that altered CD55 and CD59 on RBCs of CKD patients might play a role in the increased susceptibility to hemolysis, leading to the development of anemia in this group of patients [29].

Eldewi et al. showed that the proportion of erythrocytes expressing CD35, CD55 and CD59 was significantly lower in both pediatric and adult chronic kidney disease (CKD) patients than in healthy controls. Since all patients were anemic, this may suggest that altered expression of these proteins on erythrocytes of patients with CKD might play a role in the development of anemia [30].

\section{Conclusion}

Low levels of $\mathrm{CD} 55, \mathrm{CD} 59$, and $\mathrm{CD} 35$ in $\beta$-thalassemia major patients indicate a role for them in the aetiopathogenesis of haemolysis in this disease, and also this defect in the complement system may be responsible for the chronic complications seen in these patients. Further studies concerning the synthesis and destruction of the CD55, CD59, and CD35 proteins at the molecular level are needed to clarify the process under which the low expression is happening and this will provide a positive effect on the prognosis of $\beta$-thalassemia major patients. Further studies of CD55, CD59, and CD35 as potential therapeutic targets for $\beta$-thalassemia major patients. Exploration of CD55, CD59, and CD35 measurement in infancy or childhood as disease severity markers for development of preventative treatment strategies for children with ineffective erythropoiesis.

\section{Acknowledgements}

The authors would like to thank the staff and patients of the outpatient clinic of Internal Medicine at Ain Shams University Hospitals who agreed to participate in the study. 


\section{Conflicts of Interest}

The authors declare no conflicts of interest.

\section{References}

[1] Ahmed Kiani, R., Anwar, M., Waheed, U., Asad, M.J., Abbasi, S., et al. (2016) Epidemiology of Transfusion Transmitted Infection among Patients with $\beta$-Thalassaemia Major in Pakistan. Journal of Blood Transfususion, 2016, Article ID: 8135649. https://doi.org/10.1155/2016/8135649

[2] Thein, S.L. (2017) Genetic Basis and Genetic Modifiers of $\beta$-Thalassemia and Sickle Cell Disease. In: Malik, P. and Tisdale, J., Eds., Gene and Cell Therapies for Beta-Globinopathies, Springer, New York, 27-57. https://doi.org/10.1007/978-1-4939-7299-9_2

[3] Dong, A.C. and Rivella, S. (2017) Gene Addition Strategies for $\beta$-Thalassemia and Sickle Cell Anemia. In: Malik, P. and Tisdale, J., Eds., Gene and Cell Therapies for Beta-Globinopathies, Springer, New York, 155-176.

https://doi.org/10.1007/978-1-4939-7299-9_6

[4] Koh, D.X.R., Raja Sabudin, R.Z.A., Mohd Yusoff, M., Hussin, N.H., Ahmad, R., et al. (2017) Molecular Characterisation of $\alpha$ - and $\beta$-Thalassaemia among Indigenous Senoi Orang Asli Communities in Peninsular Malaysia. Annals of Human Genetics, 81, 205-212. https://doi.org/10.1111/ahg.12201

[5] Geller, A. and Yan, J. (2019) The Role of Membrane Bound Complement Regulatory Proteins in Tumor Development and Cancer Immunotherapy. Frontiers in Immunology, 10, Article No. 1074. https://doi.org/10.3389/fimmu.2019.01074

[6] Mamidi, S., Hone, S. and Kirschfink, M. (2017) The Complement System in Cancer: Ambivalence between Tumour Destruction and Promotion. Immunobiology, 222, 45-54. https://doi.org/10.1016/j.imbio.2015.11.008

[7] Macor, P., Capolla, S. and Tedesco, F. (2018) Complement as a Biological Tool to Control Tumor Growth. Frontiers in Immunology, 9, Article No. 2203. https://doi.org/10.3389/fimmu.2018.02203

[8] Killick, J., Morisse, G., Sieger, D. and Astier, A.L. (2018) Complement as a Regulator of Adaptive Immunity. Seminars in Immunopathology, 40, 37-48. https://doi.org/10.1007/s00281-017-0644-y

[9] Blom, A.M. (2017) The Role of Complement Inhibitors beyond Controlling Inflammation. Journal of Internal Medicine, 282, 116-128.

https://doi.org/10.1111/joim.12606

[10] He, J.R., Xi, J., Ren, Z.F., Qin, H., Zhang, Y., et al. (2012) Complement Receptor 1 Expression in Peripheral Blood Mononuclear Cells and the Association with Clinicopathological Features and Prognosis of Nasopharyngeal Carcinoma. Asian Pacific Journal of Cancer Prevention, 13, 6527-6531. https://doi.org/10.7314/APJCP.2012.13.12.6527

[11] Kurtoğllu, A.U., Koçtekin, B., Kurtoğlu, E., Yildiz, M. and Bozkurt, S. (2017) Expression of CD55, CD59, and CD35 on Red Blood Cells of $\beta$-Thalassaemia Patients. Central European Journal Immunology, 42, 78-84. https://doi.org/10.5114/ceji.2017.67321

[12] Hassan, T.H., Salam, M.M.A., Zakaria, M., Shehab, M., Sarhan, D.T., et al. (2019) Impact of Genotype of Beta Globin Gene on Hepatic and Myocardial Iron Content in Egyptian Patients with Beta Thalassemia. Indian Journal of Hematology and Blood Transfusion, 35, 284-291. https://doi.org/10.1007/s12288-018-1034-x 
[13] Palla, A.R., Khimani, F. and Craig, M.D. (2013) Warm Autoimmune Hemolytic Anemia with a Direct Antiglobulin Test Positive for C3 and Negative for IgG: A Case Study and Analytical Literature Review of Incidence and Severity. Clinical Medicine Insights Case Reports, 6, 57-60. https://doi.org/10.4137/CCRep.S11469

[14] Sayani, F.A. and Kwiatkowski, J.L. (2015) Increasing Prevalence of Thalassemia in America: Implications for Primary Care. Annals of Medicine, 47, 592-604. https://doi.org/10.3109/07853890.2015.1091942

[15] Meulenbroek, E.M., Wouters, D. and Zeerleder, S. (2014) Methods for Quantitavive Detection of Antibody-Induced Complement Activation on Red Blood Cells. Journal of Visualized Experiments, 83, e51161. https://doi.org/10.3791/51161

[16] Berentsen, S. and Sundic, T. (2015) Red Blood Cell Destruction in Autoimmune Hemolytic Anemia: Role of Complement and Potential New Targets for Therapy. BioMed Research International, 2015, Article ID: 363278. https://doi.org/10.1155/2015/363278

[17] Brodsky, R.A. (2015) Complement in Hemolytic Anemia. Blood, 126, 2459-2465. https://doi.org/10.1182/blood-2015-06-640995

[18] Obaid, J.M., Abo El-Nazar, S.Y., Ghanem, A.M. and El-Hadidi, A.S. (2014) Expression of CD55 on Red Blood Cells of $\beta$-Thalassemia Patients. Hemoglobin, 38, 339-344. https://doi.org/10.3109/03630269.2014.935787

[19] Zahran, A.M., Shaltout, A.S., Hamada, I.H., Mohammed, A.M., Abo Elgheet, A.M., et al. (2020) Assessment of Complement Regulatory Proteins CD55 and CD59 on Erythrocytes in Beta-Thalassemia Major Patients. Egyptian Journal of Immunology, 27, 109-118.

[20] Alegretti, A.P., Schneider, L., Piccoli, A.K., Monticielo, O.A., Lora, P.S., et al. (2012) Diminished Expression of Complement Regulatory Proteins on peripheral blood Cells from Systemic Lupus Erythematosus Patients. Clinical and Developmental Immunology, 2012, Article ID: 725684. https://doi.org/10.1155/2012/725684

[21] Obaid, J.M., Abo El-Nazar, S.Y., Ghanem, A.M., El-Hadidi, A.S. and Mersal, B.H. (2015) Compensation of CD55 Underexpression on Red Blood Cells of $\beta$-Thalassemia Major Patients. Hemoglobin, 39, 184-189. https://doi.org/10.3109/03630269.2015.1029588

[22] Dambal, A., Nimbal, N.V. and Kalsad, S.T. (2015) Paroxysmal Nocturnal Haemoglobinuria Masquerading as Malaria: A Case Report. Journal of Clinical and Diagnostic Research, 9, OD03-OD04. https://doi.org/10.7860/JCDR/2015/13465.6329

[23] Salama, M.A., Sadek, N.A., Hassab, H.M., Abadeer, A.F. and Mikhael, I.L. (2004) Erythrocyte Autoantibodies and Expression of CD59 on the Surface of Red Blood Cells of Polytransfused Patients with Beta-Thalassaemia Major. British Journal of Biomedical Science, 61, 88-92. https://doi.org/10.1080/09674845.2004.11732650

[24] Kumar, R., Singh, K., Panigrahi, I. and Agarwal, S. (2013) Genetic Heterogeneity of beta Globin Mutations among Asian-Indians and Importance in Genetic Counselling and Diagnosis. Mediterranean Journal of Hematology and Infectious Diseases, 5, e2013003. https://doi.org/10.4084/mjhid.2013.003

[25] Opi, D.H., Uyoga, S. and Orori, E.N. (2016) Red Blood Cell Complement Receptor One Level Varies with Knops Blood Group, $\alpha^{+}$Thalassaemia and Age among Kenyan Children. Genes and Immunity, 17, 171-178. https://doi.org/10.1038/gene.2016.2

[26] Veerreddy, P. (2013) Hemoglobinuria Misidentified as Hematuria: Review of Discolored Urine and Paroxysmal Nocturnal Hemoglobinuria. Clinical Medicine Insights: Blood Disorders, 6, 7-17. https://doi.org/10.4137/CMBD.S11517 
[27] Arora, M., Kumar, A., Das, S.N. and Srivastava, L.M. (1998) Complement-Regulatory Protein Expression and Activation of Complement Cascade on Erythrocytes from Patients with Rheumatoid Arthritis (RA). Clinical and Experimental Immunology, 111, 102-106. https://doi.org/10.1046/j.1365-2249.1998.00449.x

[28] Barros, M.M., Yamamoto, M., Figueiredo, M.S., Cançado, R., Kimura, E.Y., et al. (2009) Expression Levels of CD47, CD35, CD55, and CD59 on Red Blood Cells and Signal-Regulatory Protein- $\alpha, \beta$ on Monocytes from Patients with Warm Autoimmune Hemolytic Anemia. Transfusion, 49, 154-160.

https://doi.org/10.1111/j.1537-2995.2008.01936.x

[29] Al-Faris, L., Al-Humood, S., Behbehani, F. and Sallam, H. (2017) Altered Expression Pattern of CD55 and CD59 on Red Blood Cells in Anemia of Chronic Kidney Disease. Medical Principles and Practice, 26, 516-522.

https://doi.org/10.1159/000481823

[30] Eldewi, D.M., Alhabibi, A.M., El Sayed, H.M.E., Mahmoud, S.A.K., El Sadek, S.M., et al. (2019) Expression Levels of Complement Regulatory Proteins (CD35, CD55 and CD59) on Peripheral Blood Cells of Patients with Chronic Kidney Disease. International Journal of General Medicine, 12, 343-351.

https://doi.org/10.2147/IJGM.S216989 